
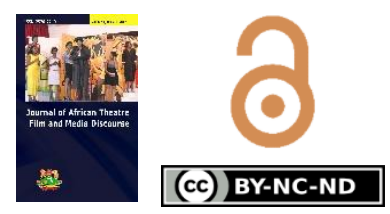

Journal of African Theatre, Film and Media Discourse

Volume 1, Issue 1, 2017

(C) 2017 The Author(s)

This open access article is distributed under a Creative Commons Attribution (CC-BY) 4.0 license.

Article Information

Submitted: $9^{\text {th }}$ January 2016

Accepted: $5^{\text {th }}$ October 2016

Published: $2^{\text {nd }}$ April 2017

Conflict of Interest: Co-author is a member of the editorial board

Funding: The co-author is a member of the editorial board

Additional information is available at the end of the article

(c)

https://creativecommons.org/li censes/by/4.0/

ISSN 2520-7210

\section{Female Mask/Masquerade in Nigeria, Aesthetics and the Art of Secret Societies}

\section{Esther Akumbo Nyam}

Department of Theatre Arts, Plateau State University, Bokkos

\section{Abstract}

The Dramatic performance by actors in masks and costumes still remains enigmatic. The ideological context of mask, and masquerade in Africa is associated with the spirit world which is an act of secret society dominated by men's world. This paper focused on the role, performances and contributions of women in masquerade performances in Nigeria. The symbolism of women's aesthetics, cosmology, mythology, performance, Genre, audience participation, construction, and originators and custodians of mask and masquerade is highlighted as emerging trends of feminist discuss in contemporary theatre performances as central to women liberation in men's dominated society. The paper concludes the role and place of women in taking the masquerade performances, economic, social, political, culture empowerment from it's inception as custodians of Spiritism.

Keyword: aesthetics, mask, masquerade, performance 


\section{I.0 Introduction}

Mask/masquerade play as a very vital role in African culture and is served for several purposes. Mask and masquerade performances and its aesthetics is not unique to Africans alone. It is a universal idiom. These were a deliberate creation, a tool, an artifact, a thing of expressive beauty and power which lies two primitive religious beliefs (referred to as) animalism and totemism. They all play a most important part in ancestor worship from which true drama arose. Kenneth \& William (1956:9).Masquerade can be term as a form of ancestral manifestation, consoles themselves in the believes of spirits, re-incarnation, believing that man does not die in African cosmic law, he only progresses towards ancestral hood. Sainsbury (1990:8I) opines that masquerade are intended by their performances to convey certain attributes and qualities of ancestral spirits, power, strength, speed and knowledge. The very nature of African Masquerades which we shall concern ourselves encompassing a disguise of the human face, elaborate costuming, choreography and musical accompaniment imbues the performance with aesthetic power and mystery that appeals to adults and children alike. This has attracted scholars in mask and masquerade performances. It has drawn their attention to its relevance in the socio, political and economic life of the people. Illah (1983) opines that festive and entertaining masquerades play a critical role in the aesthetic interpretation of a community's history, culture and identity. The tenet here is that mask dancers disguised as animals, spirits, ancestors or ordinary human beings enact well known legends and stories who also celebrate important community events. Masquerades are frequently part of serious religious ceremonies, such as those, relating to initiations and funerals. Numerous masquerades that poke fun of individuals and groups are also the present trend in contemporary Nigerian theatre performances such as National festival of arts and culture and carnivals. The contemporary masquerade performances in Nigeria has rested more on the aesthetics and socio-economic aspect of its presentations. This has lost most of the religious ideas and history. At first sight, it still appears to have all the essence, vitality and prestige. In the rural areas, one sees only reflection of its more glorious past, but even that is dwindling its importance as the people become more and more used to western ideas. In Urban areas, festivals such as carnivals and National festivals of Arts and culture have made the masquerade performances common. The people watch their performances at a close quarters. They pay the masquerades respect which traditional etiquettes prescribes. Appearances and performances of women's participation and custodians of masquerade has also been silent over time. This chapter therefore, analyses the mask, masquerades, aesthetics, and costumes, involvement of women as carvers and custodian of masquerades and its performances.

\subsection{Nigerian Masquerades: The Kalabari ljaw Masquarades of the Niger Delta. Historical background}

According to Vogel (1997:172). The Kalabari ljaw people live in some thirty villages in the tidal zone of the Niger Delta. Formed a district sub-group and culture among ljaw who are 
predominantly engaged in fishing, farming and trading in their canoes. In the past, even the skilled carvers came from the hinterland to work in the coastal regions in return for fish. The accessibility and possibility of wide communications in the coast is important in any study of south-east Nigeria art, particularly in understanding the movement of masquerades and art forms from tribe to tribe. The art form of some fisher people often directly reflects their way of life (owu) water spirit are specifically associated with the sea and ljaw fishing economy. This is what Finnegan (1970) describes as a pretence or disguise won at such a function.

Water is almost never an obstacle in the diffusion of culture; an example of this is the spread of a belief in a water goddess, "mamiwata" (Pigin English) to mean "mother of the waters." This goddess are also found in Ivory Coast to the Cameroun. The ljaw's are rich in religious assemblies, ceremonies and masquerades with common traditions and myths. The name "Ekine" comes from the goddess of the spirit of the water, but within the masquerade, each of the numerous water spirits or water people has its own dance in which he or she is entertained by members. Who are these water spirits who are represented in mask and mime? Fist of all, they are lords of the creeks who are thought to live in fabulous villages under the water decked out in coral and gold land fine clothes. They are anthropomorphic and zoomorphic or mixture of the two natural forces, human characters, rainbows, pythons, fish. At some point in the development of kalabari culture, the story image of lkaki was taken up as the theme of a masquerade. How, when and where this happened, we shall never know for certain. Kalabari, it is true, give a clear cut account of the matter; but their account smacks more of myth than of history. Ogundeji (2000:2I) describes this myth as: citizens of heavens who are involved in entertainment and edification through performances. Kalabri believe that the Ikaki play was first introduced in the long defunct village of Oloma, in the creeks west of the mouth of the back of the village-a kind of supernatural supertortoise. Ikaki use to come out of the forest to dance; and when ever he did so, the villagers gathered round to watch him. They found his dancing splendid, and they always pestered him to come back, but each time he comes out, he warned them in song, but persisted in calling him. One day, on invitation, he came out with a finer dance than ever before. As he danced, he sang, he lifted his leg, and all the people living in that direction died. Then the lkaki vanished into the forest and was never seen again.

\subsection{Nature of Performance}

The lkaki is now perform in this community in form of Dramatic representation. Ikaki begins in the usual manner of Ekine plays. Clever and unscrupulous as he is, Ikaki of the play falls in love with a silly woman and marries her, then begets and adores a witless child. Between them, wife and child undo many of his best laid schemes. In the play, indeed the "undoing" is as much in the evidence as the "doing" of lkaki. People laugh from out of the depth at ravening forest beast, because for once they have got him behind bars. It is a little puzzling to find that in the context of story telling, lkaki is regarded as a purely fictional 
character, whilst in the context of masquerade dancing he is regarded as a nature spirit (owuamabo).The explanation seems to be that the Ekine masquerade society focused from the beginning on plays representing the owuamabu. Hence any new play brought into the society, no matter what it's actual inspiration, tended to acquire a mythical charter which brought it into line with the general scheme of inspiration by contact with this class of spirits. Horton (1963:493) describe the kalabari as people with unique culture on association representing the water spirits. Ekine society, according to the Kalabari, was introduced by a goddess similar in nature to the village heroes who came from outside the village, taught men how to make the mask and masquerade dance and care for the shrines and then left. Robert (1980:82).

\subsection{Cosmology}

The value which Ekine sets on the dancer's attunement to the drum does much to explain why its members consider possession by the masquerade spirits to the crowning achievement of the expert performer. In Kalabari thought, all symbols of the gods are instinct with their present. Now the drum-rhythms of each masquerade are symbols of it's spirit "owner", and as such, they too are vehicles of his presence. So, saying that the spirit owner has taken charge of the dancer's body is a natural way of describing the ideal state of attunement in which the drum-rhythms seen to have taken over the man's movements from his conscious will and thought. That this are indeed two ways of describing the same experience is suggested by the reply of a gifted dancer whom was asked what was like to become possessed during the dance. Robert (1980) puts it: one plays until, as it were, the drum pushes one around.

\subsection{Convention/Aesthetics}

Ruth (1970:5 I3) describes African performances as quasi. Most of the criteria we apply to European and classical art must also be applied to African art as whether they be esthetic, sociological or economical. Thus, brilliant works of art in Africa are not just accidental products of certain religious, pre-occupations, a kind of primitive mentality which throws up stupendous stylized masks or abstract figurines as if by magic. The African sculptor normally works for gain, spiritual purpose, money, goods in kind, a wife or at least prestige (Robert, 1980:492). The beauty and types of Kalabari Ekine masquerades are in their head gears and costumes. The Ikaki masquerade is fairly and simply dressed, is readily recognizable by his hunch back and by the schematized tortoise body which is his head piece. He comes out with a canny, mincing step. Nimite Poku, dressed mainly in a soiled blue and white sheet topped with an old felt hat, follows his step with a paddle sloped over his shoulder

\subsection{Mask/Mythology}

The wood used for the mask by kalabari people is a tough hardwood of the common mangrove and is the standard wood for the sculptors of the water spirits since "emo" 
(Mangrove) comes from the creeks and that is the place of the water spirits. First and foremost, the kalabari sculpture is an instrument for localizing the spirit it represents. But the spirit, what is it? The essence of the spirits is thought to be contained in the masks and sculpted head dresses which is perform during these masquerades and functions as symbols of the spirit during invocation and sacrifice before the dance. It is though that the mask leads the dancers since he is possessed by the masquerade spirit owner. It is believed that the water animals are thought to become spirits through metamorphosis after reaching a certain age, there is no evidence of the exact nature of these animals apart from the elements in the masks. It would be clear, however, from the type of animals depicted in the mask and their role in myth and ritual-crocodile, hippotamus, shark, jelly-fish that they are not of great economic significance. The fact that the water spirits are depicted features of water animals combined with features of the human head reflects kalabari and other cultures in Nigeria belief that the spirits are half human and half animal. The mask, localizing the spirit of the animal becomes the important element in the dramatic representation. The spirit is summoned and controlled and confined to the sculpture and it is the spirit which guides or possesses the actor who is the vehicle only for its dramatic presentation. The priest who is usually also the masker, then dresses in clothes symbolic of the spirit and gives the performance often in a state of possession.

\subsection{The Power Balancing Theory}

The balance power theory is an old concept in the history of man. It is premise on the minimum tendency and maximum of a lawlike recurrent equilibrium in which power is checked and restored to ensure the survival of the subjected (Vasquez \& Collins 2003).The epochal attest to this fact that women from past history have been originators of mask making and performances. From the history of Ekine society, according to the Kalabari people, was introduced by a goddess who came from outside the village, taught men how to make the mask dance the masquerades dance and carte for the shrine and left (Holas, 1969) sums it up that:
Masquerade is a recurrent mysthical pattern in West Africa whereby men assume control of what women originate, and reflects that women are all important in so far as they bring men into the world, but men through cunning, have acquired dominance (Holas, 1969, p.84)

In few places however, very elderly women become initiates but are not allowed into the masquerade house when preparations for a display are going on. Rhetorical questions at this point is important, such as, at what point are women expected to stay away, and what are their roles in the performances? Women play fundamental arrangement in masquerade performances and initiations. 
Through the use of play

Through semiotic pictures

Mask making

And masquerade performances

Robert (1980) opines that:

"Women do not play an entirely negative role in African performance. There are few women carvers, but many in the field of pottery, weavers, visuals and masquerade experts, their contribution is indeed a major one. Moreover, women provide many of the themes of art and the rites of passage which concern them - betrothal, puberty rites, marriage and death (Robert, 1980, p.82)

There has also been a traditional explanation for African masking, particularly when it concerns the so-called secret societies that I maintained sex polarity and the dominance of men over women and the restricted social and economic role of women in the face of changing conditions. It is also true that some societies restricted their performances and the viewing of their secret to members, and excluded all women and children and noninitiates. Many more depended on women as their cooperative audience and often participant observers. The "omele" cultural festival of the Gwandara Garaku people in Keffi local government in Nasarawa State captivated the researcher's interest while in high school as a good example. The festival opens with their masquerades in display and a young female virgin between the age of seven (7) to eleven (II) years takes the lead all through the festival. The festival is celebrated once every year for cleansing of the community, for the gods to give them bountiful harvest, fertility and protection over their territory. During this festival, a female virgin is chosen within the community while six (6) masquerades in number follow the virgin as they walk round the town, dancing, pouring libation upon the land; invoking the spirit of their ancestors to take charge. In an interview with his Royal Highness, the Ambaga of Toni in Garaku says, "To the Gwandara people, masquerade performance during omelet festival is necessary because, it signifies the presence of the ancestral spirits which is seen in their chanting and the dancing while the members of the community follow behind in agreement with the virgin until they settle finally at the shrine with the virgin going in first. The female virgin signifies purity. The "Odu masquerades" among the Alago people of Nasarawa state in an interview with Suleiman Adokwe opine that "the Alago people" allow women to participate during masquerade performances, this system of performances is been handed from generation to generation. A woman usually accompany's the main mask "The Odu" as its handmaiden, wiping its brow and fanning the masquerade when it is tired, also ready to adjust a heavy mask if it slips, at the same time collecting money and gifts from appreciative audience.

Today, these societies exist primarily to entertain the public despite their roles in the past. In all these societies, it is the mask which matters. It is the mask which performs 
and for this reason the identity of the masker is unimportant and should not be known. The mask surprises the public, appearing from the forest as if by magic for a second or two in the world of men. Women as wives, mothers, spirits and ancestors are portrayed and displayed in masquerade performances. Figures and masks are made to represent women and depict an ideal of female beauty, not because women had to be fertile or were important reference points in a descent system. Among the Dogon people of Zaire, certain female masks were executed for no other reason than that the models for them and vividly impressed the carver by their beauty. In the execution of female ritual masks worn by itinerant dancers, the dancers, the sculptor or carver increases the charms of the mask, as well as its efficiency by taking a well-known beauty as its model, reproducing her individual hair style and cicatrisation. Among the Ishokwe, the dance mask "Pwo" of Zaire, the female version of the male mask is the image of a female ancestor and is supposed to encourage fertility by depicting the hairstyle, tattoos and features of an ideal Ishokwe beauty. Also among the lgbos, Onuora (1980:135) postulates masquerading in lgbo land as sacred and important to the community. Mask in lgbo land are often carved to portray beautiful spirit maidens in a refined and delicate style; the masks are small with shapy defined features. These maiden spirits are said to represent beautiful local girls and in most of them, we have an idealized type of lgbo beauty.

\subsection{Masquerades and Patrons}

In Africa as in Europe, Art needs patronage; the patrons or founder are either chiefs, elders, societies or lineages before they are made, and it is the disappearance of patron in some form or other are reasons for the decline in African performances. Founder patron are therefore very important in masquerade performance. What then are their roles? The founder patrons are the decision makers of such masquerades. The founder according to Igala customs and tradition must be a custodian of the initiates of the masque (Illah 1983). He determines what type of masquerade to find. It determines the resources and duration of the mask, must be a carver so as to determine what impression he wants on the mask i.e. issues of conventions and Genre; knowing the type of mask to make whether a woman or an animal etc. He determines whether it's serious (ritual) or social masquerade example, the Igala people in Kogi state have the "Adaka masquerade" which is non dancing masquerade just for entertainment and not ritual. The Agba masquerade is purely for dance entertainment which is use for competition. The founder is responsible for rehearsal and must also find musicians or orchestra or hire the instruments. Rehearsal starts in forest location because it is believe to be metaphoric and quiet. Costumes and accessories like beats, colours are put in place. On the eve of the festival, they untake the founding of the masquerade that is anticipating the arrival of the ancestral presence in a theatrical form and he must be found on the day of the performance

\subsection{Conclusion}


Anybody who has attended masquerade performance will agree that enjoyment of the performance and visual appreciation of the masks play more than minor role even during religious, social, funeral and leisure ceremonies. Masquerade performances is therefore applicable to all culture whether European or African, every culture builds a story or experiences round their masquerades and also attach great importance in masquerades as spiritual or ritualistic beings discussed in this presentation among the Niger Delta, Northern regions, and other parts Africa. Despite the changing trends that is over taken masquerading and left it a monument to a vital principle of traditional religion among the people, it is developing among other channels. It has now become an entertainment and a source of amusement in their lives. Female involvement in masquerade performance among these regions play a vital role which is reflective in their performances in Nigeria and Africa at large. From the research findings, it has shown that women should be acknowledged as originators and appreciated in both the production and performances of mask and masquerade performance. Masquerade performance is an aspect of the theatre that should be given serious consideration in area of preservation, documentation and performances in a changing society like ours. How is it achieved? Through patronage. The making of mask and masquerade is capital intensive in Africa. Arts need patronage because they are the sole financiers of masquerades. Lack of patrons in some form has caused the decline in African art in the twentieth centure. Appreciate their performances: most of the criteria we apply to European and classical art must also be applied to African arts - whether they be aesthetic, sociological or economical. Full encouragement, involvement and participation of women in mask and masquerade performance. From the findings, women in Africa are traditional carvers as well, who have found a strong source of patronage in masquerading. They have also contributed towards the accentuation of these qualities. The masks they produce as such are essentially communicative and symbolic and should be promoted. The brilliant works of arts therefore are not just accidental products of certain religious preoccupations, a kind of primitive mentality which throws up stupendous stylized masks or abstract figurines as if by magic, but a wonderful piece of arts that can benefit the people both economically, socially and should be appreciated. 